INTEGRATED SEED SECTOR DEVELOPMENT PROJECT ETHIOPIA

\title{
Training manual on Seed Producer Cooperatives (SPCs)
}

\section{MODULE | Organization and management of SPCs}




\section{Colophon}

Lead authors | Muhsin Yimam and Tadesse Teshome

Contributors | Alemayehu Assefa, Demeke Samaro, Minilek Kefale, Solomon Petros and Jo Weeks

Editors | Amsalu Ayana, Herman Snel and Jo Weeks

Photography | Lex Schmeetz, Mirjam Schaap and ISSD Ethiopia

Design | Anita Simons, www.symsign.nl

Please cite as | WCDI (@2020) Local seed business management, Module: Organization and management of SPCs; December 2020. Commissioned by the programme on Integrated Seed Sector Development in Ethiopia (ISSD Ethiopia). Wageningen Centre for Development Innovation, Wageningen University \& Research.

Wageningen Centre for Development Innovation supports value creation by strengthening capacities for sustainable development. As the international expertise and capacity building institute of Wageningen University \& Research we bring knowledge into action, with the aim to explore the potential of nature to improve the quality of life. With approximately 30 locations, 6,500 members (5,500 fte) of staff and 12,500 students, Wageningen University \& Research is a world leader in its domain. An integral way of working, and cooperation between the exact sciences and the technological and social disciplines are key to its approach.

\section{(cc) BY-NC}

The Wageningen Centre for Development Innovation uses a Creative Commons Attribution 4.0 (Netherlands) licence for its reports. To view a copy of this license, visit https://creativecommons.org/licenses/by-nc/4.0/

This report can be downloaded for free at https://doi.org/10.18174/536872 or at www.wur.eu/cdi (under publications).

This work was commissioned by Integrated Seed Sector Development in Ethiopia (ISSD Ethiopia), a programme of the Bilateral Ethiopia Netherlands Effort for Food, Income and Trade (BENEFIT) partnership funded by the Netherlands Ministry of Foreign Affairs through the Embassy of the Kingdom of the Netherlands in Addis Ababa, Ethiopia. ISSD Ethiopia is implemented by the consortium of Bahir Dar University, Haramaya University, Hawassa University, Mekelle University, Oromia Seed Enterprise, and Wageningen Centre for Development Innovation, which is a part of Wageningen University \& Research, in collaboration with the Government of Ethiopia and many others across research, industry and civil society in Ethiopia.
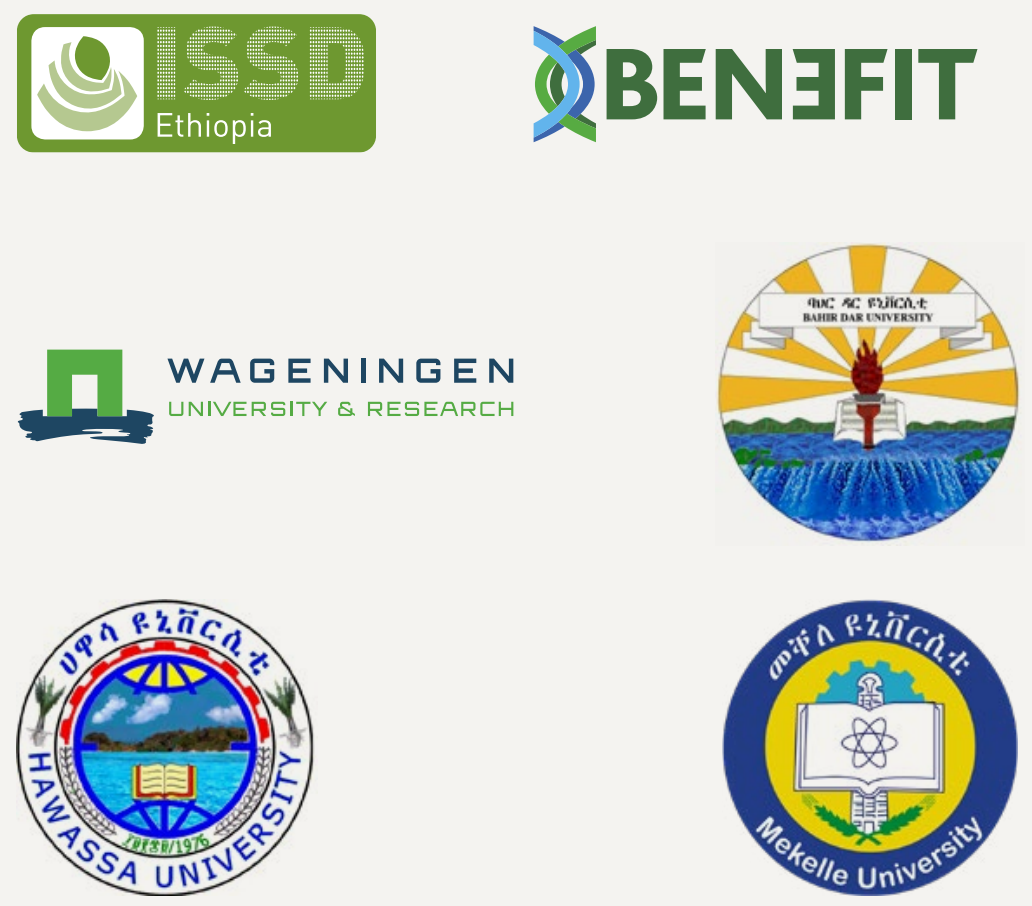

Government of the Netherlands

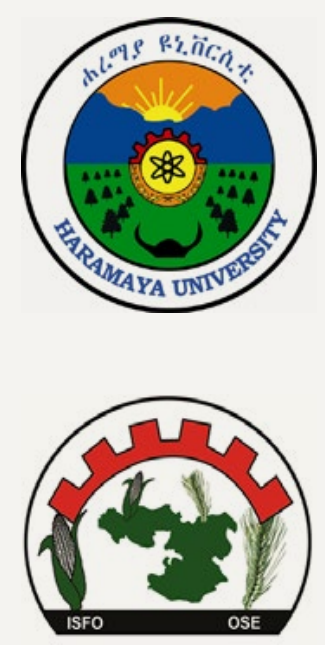




\section{Contents}

Organization and management of seed producer cooperatives

Definitions

Section 1: The local seed business model for SPCs

1.1 Criteria used to organize SPCs

1.2 Access to seed business resources: the SPC resource pentagon

1.3 Steps for organizing SPCs

Section 2: The organizational structure of SPCS

Section 3: Management of SPCs

3.1 Key characteristics of effective SPC organizational management 16

$\begin{array}{ll}3.2 & \text { Autonomy } \\ 3.3 & 17\end{array}$

3.3 Why division of tasks is important in the organizational structure of SPCs 18

3.4 Key tasks of the SPC management committee

4.2 Don'ts 


\title{
Organization and management of seed producer cooperatives
}

\author{
This training module aims to support the capacity building processes of \\ professionals involved in the strengthening of SPCs in Ethiopia. By zooming \\ in on elements related to the organization and management of SPCs, it builds \\ on the previous module's focus on the sound governance of SPCs.
}

Trainers can make use the information and facts from this manual as input to tailor design their own training sessions. The assignments and reflection questions in this manual can be used as inspiration to engage participants through interactive training sessions that build on their personal experience and insights.

This module brings together experience and learning from the Integrated Seed Sector Development Programme in Ethiopia (ISSD
Ethiopia) that operates within the BENEFITPartnership programme in six regions.

This module consists of four sections; it is suggested that each one could be tackled in a separate training session:

- The local seed business model for SPCS

- The organizational structure of SPCS

- Management of SPCs

- Do's and don'ts.

\section{General learning objectives}

By the end of this training module, participants will have learned about and be able to discuss the following questions.

- What is the LSB model, and how does this apply to SPCS?

- What are the key features of the organizational structure of SPCs?

- What are the key management functions of SPCs?

- From others' experience, what are some do's and don'ts for SPC organization and management? 


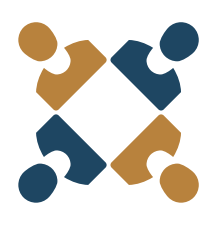

\section{Reflection questions}

Pair up participants to reflect on the following questions.

- What do you understand by the organizational management of SPCs?

- Revisit this question at the end of the module.

\section{Definitions}

An organization is a combination of people working together in pursuit of certain common purposes or specified goals called organizational goals. These may be to:

- make profit (a business organization)

- spread knowledge (an educational organization)

- provide social satisfaction (social clubs or societies).

According to Nwankwo (1981; cited by Soneye, 2014), "organization implies three things, namely:

a A group of persons working together for a common purpose, for instance, cooperatives, companies, school, institutions;

\section{b A network of relationships among} individuals and activities. This implies the structural and/or strategic arrangement of positions and roles; and

\section{A process of executive function aimed} at ensuring that resources, activities and authority relationships are coordinated in order to achieve specified goals."
Organizational management is the process of managing an organization with the overall aim of achieving its objectives. Organizational management functions include planning, organizing, staffing, leading, monitoring, and evaluating.

Seed producer cooperative (SPC) refers to a group of farmers organized into a cooperative form of business on a voluntary basis. The members of the SPC have a common interest and shared goals. The primary aim of the SPC is to produce and market quality seed of farmer- preferred varieties within and beyond its locality. The minimum number of members required to register a cooperative is 50 in Ethiopia (proclamation no. 985/2016, art 7; sub art 2). 


\section{SECTION 1 The local seed business model for SPCs}

This section highlights key components of ISSD Ethiopia's local seed business (LSB) model and provide insights on how this helps to organize and manage SPCs.

The LSB model, which is presented here, is grounded on years of experience in Ethiopia, Africa and Asia. The model has been proven very effective in supporting groups of farmers to become organized into SPCs. Farmers are voluntarily organized into SPCs in order to engage in seed business - be it production, processing, or marketing or a combination of these. Often initial project and public support is provided. The support helps the SPC to become an entrepreneurial seed producing and marketing organization which is technically well equipped, organized, professional, commercially oriented, and autonomous.

SPCs produce seeds of different varieties of several crops, which are mostly adapted to local agro-climatic conditions and in high demand by farmers in the locality and beyond. As such, each SPC has a local orientation, selling affordable seed to neighbouring smallholder farmers, hence targeting mar- ket segments that are neither attractive for private seed companies nor feasible for public seed enterprises. Effective SPCs have the potential to be the preferred local source of quality seeds for famers.

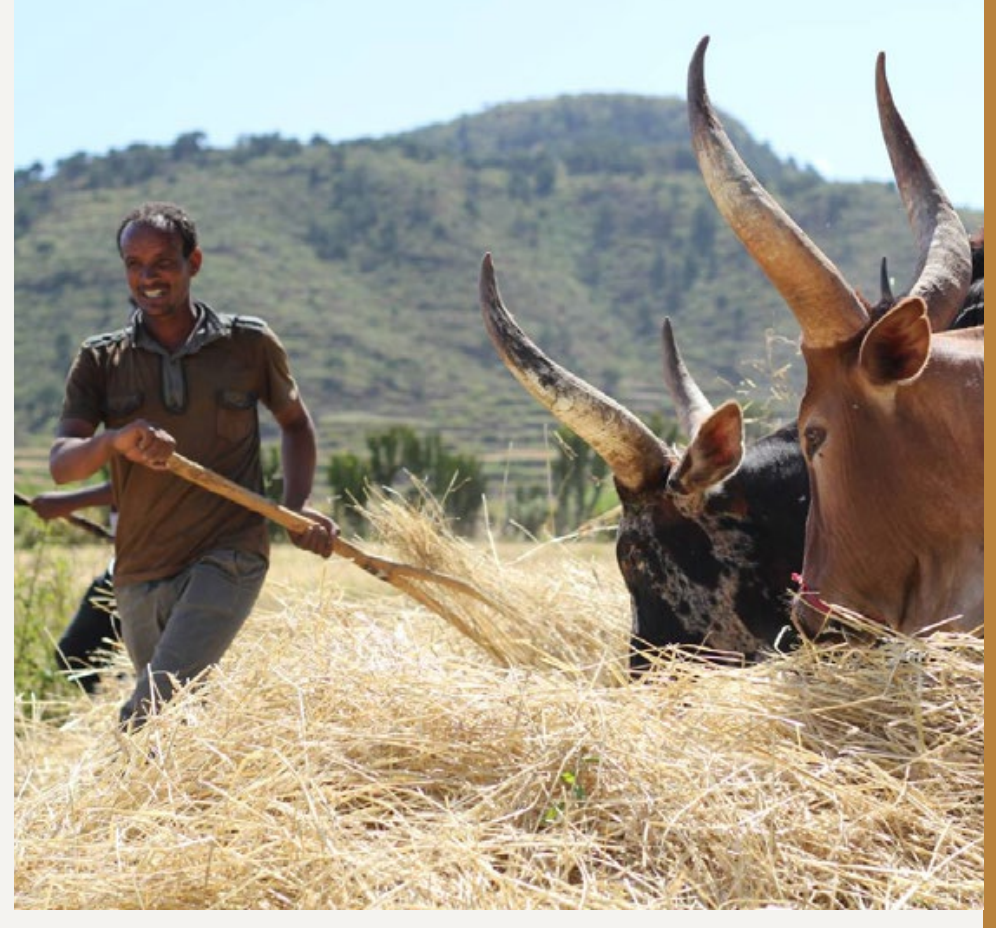




\subsection{Criteria used to organize SPCs}

SPCs need the following:

- a clear centre of operation and indication of spatial boundaries

- a minimum membership size, of not less than fifty members

- an established and functioning internal seed quality control committee

- suitable land (members' farms need to be clustered as a seed farm, which is planted to a single variety of the same crop to avoid physical and genetic admixture)

- members experienced in seed production

- a business license and certificate of competence for operation.

- A certificate of registration as a cooperative society, based on the Cooperative Society's proclamation no. 985/2016 of Ethiopia. This certificate is obtained when the SPC has fulfilled the minimum criteria of Ethiopia's Cooperative Society proclamation.

- A certificate of competence (COC) as a seed producer cooperative, based on Ethiopia's seed law no.782/2013. This certificate is obtained when a SPC has fulfilled the criteria regarding human resources and infrastructure, as stipulated in Ethiopia's Cooperative Society proclamation.

\subsection{Access to seed business resources: the SPC resource pentagon}

To effectively undertake seed business, SPC should have access to certain types of resources, which are structured according to five dimensions derived from the Sustainable Livelihoods Framework's Capital Assets Pentagon developed by the UK's Department for International Development (DFID):

Figure 1: Sustainable Livelihoods Capital Assets Pentagon

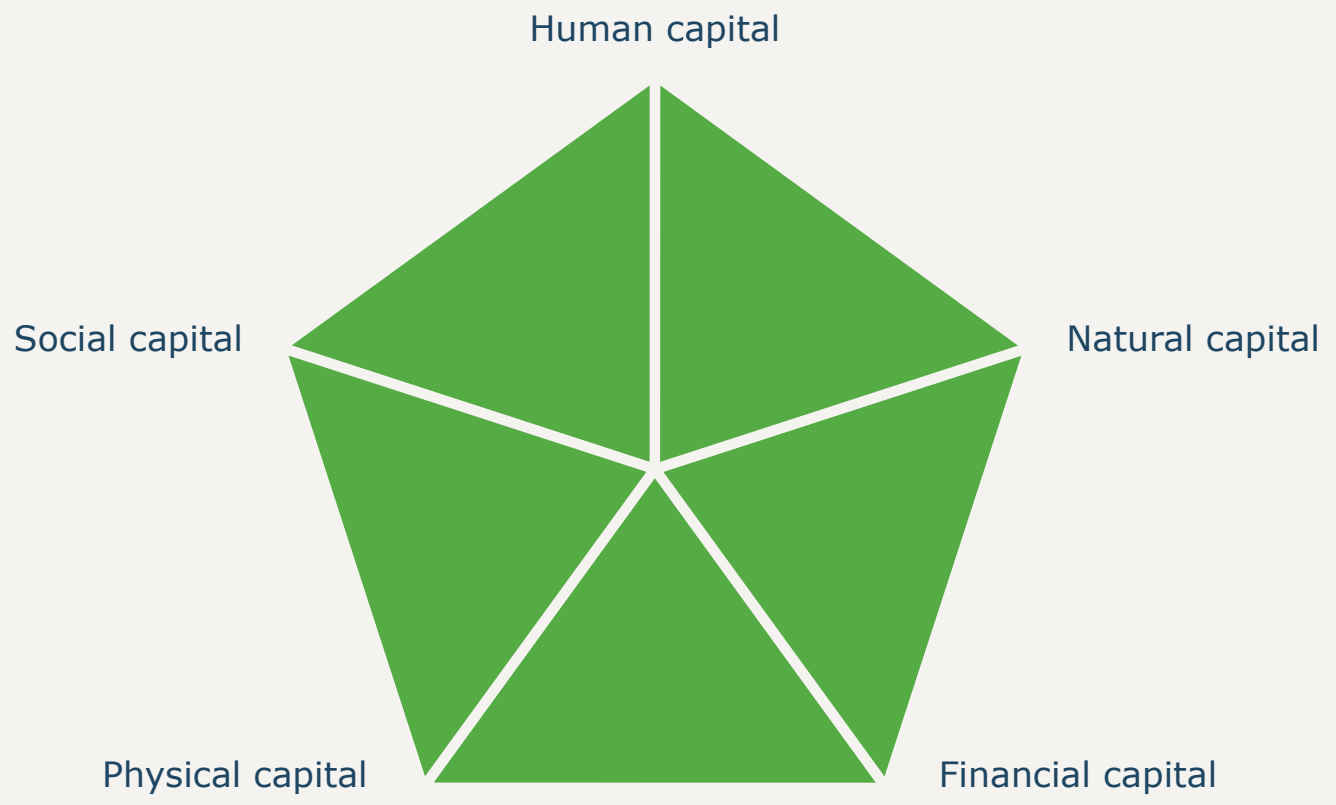


SPC resource pentagon checklist

Consider the following key elements as a basic checklist for a group of farmers that is considering starting up a SPC.

\section{Human resources}

- members experienced and skillful in seed production

- hired workers

- knowledge, skill, experiences and labour

\section{Natural resources}

- land suitable for seed production (cluster of plots for different varieties)

- water for irrigation

\section{Financial resources (in cash or in kind)}

- Members' financial shares collected (at least $40 \%$ of the share should be collected for initiating and the remaining $60 \%$ should be collected within 5 years)
- loans

- grants

- donations

Physical and material resources

- infrastructure (office, warehouse, store facilities and other structures)

- office and office equipment

- utilities (power grid/source, water and telecommunication lines

- farm machineries, farm equipment, and farm tools

- agricultural inputs (for instance, seed and fertilizer) and supplies

- processing machines and laboratory equipment

$$
\begin{aligned}
& \text { Social capital } \\
& \text { - trust } \\
& \text { - social cohesion and values } \\
& \text { - common interests (clearly defined) }
\end{aligned}
$$

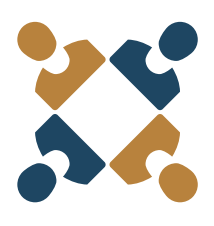

\section{Reflection questions}

In small groups, reflect on the following questions.

- How many SPCs that you know of have access to these key categories of resources?

- Does the SPCs that you are supporting or representing have access to these resources?

'- Tip: You can convert the bullets into an interactive evaluation checklist that participants carry out as a self-evaluation or in pairs, asking each other questions. 


\subsection{Steps for organizing SPCs}

Based on the experiences of ISSD Ethiopia in supporting SPCs to set up their operations, the following guiding steps could be followed to organize a particular SPC.

- Identify a potential site and group of farmers suitable for quality seed production.

- Initiate preliminary discussions with potential member farmers, local community and local partners.

- Establish a steering committee to support the initial setup of the SPC.

- Conduct a comprehensive feasibility study to:

- objectively assess whether the SPC has the potential to be a viable seed business entity

- provide a guarantee to potential members to assess if the investment is lifeworthy and has an adequate return on investment vis-à-vis other business opportunities, based on study results

- outline clearly the specific business propositions that are commercially viable and sustainable for the potential SPC in question

- answer adequately key questions regarding the viability of the potential SPC in the following areas:

- technical

- financial

- economic

- environmental

- social and political

- organizational

- describe in detail all assumptions and describe potential risk factors provide insights on specific business opportunities.
- Design a SPC governance structure and institutional set up (organogram, bylaw, memorandum of association, business plan, management structure).

- Ensure members' commitment (engaging in dialogue, financial contribution, active engagement in organization and committees).

- Facilitate the transformation of the identified farmers' groups into legal and licensed SPCs:

- check all paperwork is updated and available

- submit documents to the cooperative promotion office

- secure the appropriate certificate of registration.

- Register the SPC as a local business.

- Design and integrate the required monitoring and evaluation operations.

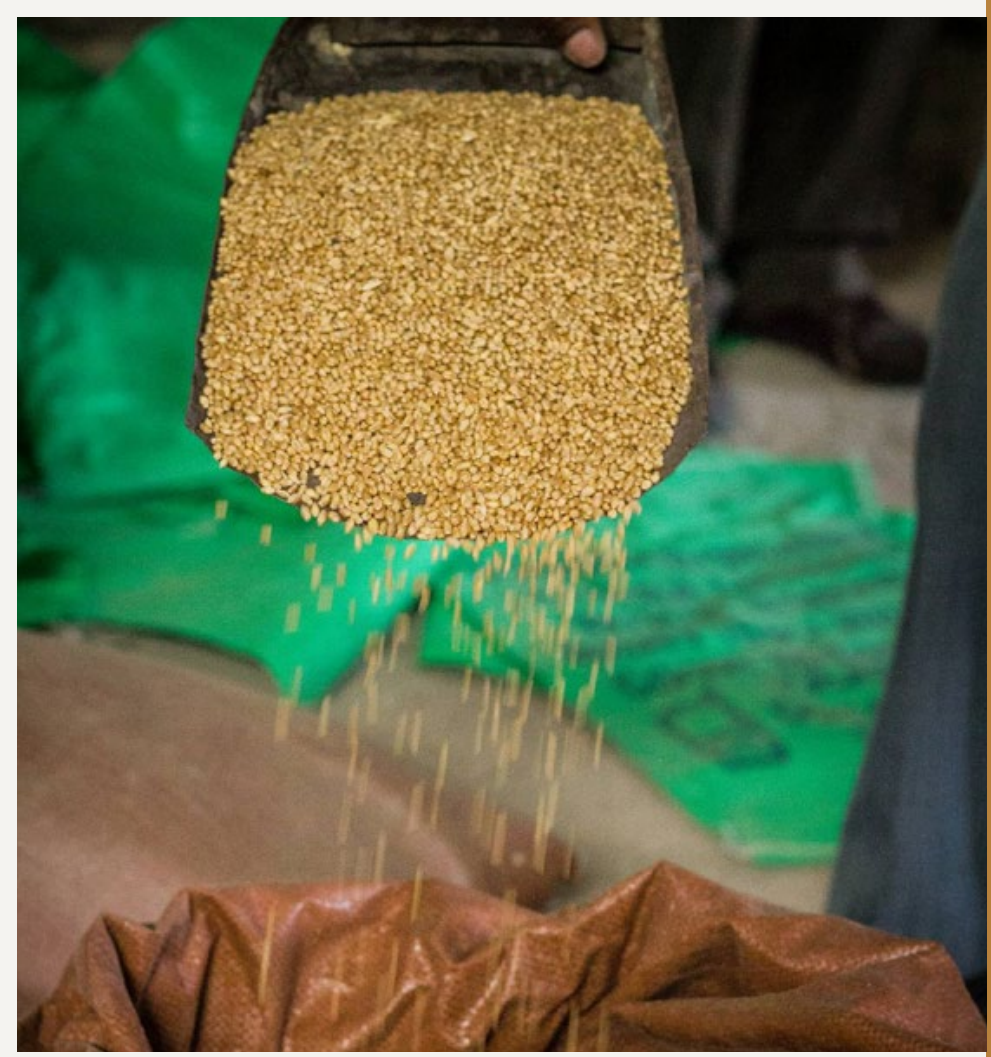


Reflection questions

In groups of three people, assess and evaluate current practices in setting up SPCs. Use the following questions to guide the conversations.

- Are all SPCs established using a preliminary feasibility study?

- Have you ever seen or read a feasibility study document for an SPC?

- Do you feel the document was clear and contained detailed and contextualized information?

- Do you know of SPCs that have been established without a feasibility study, or with an assessment that they would not be viable?

- What types of issues and limitations have you experienced with feasibility studies?

- How could SPCs monitor and evaluate their operations and strategies? 


\title{
SECTION 2 The organizational structure of SPCs
}

\author{
This next two sections revisit and build on the learning already undertaken \\ about the organization and management of SPCs covered in the module on \\ governance and leadership of SPC, section 3: SPC structure and management). \\ That module focused on how good organization and management leads to good \\ governance; the emphasis in this module focuses further on the practicalities \\ involved in achieving the SPC's objectives.
}

\section{Specific learning objectives}

- By the end of this session participants will have a clear understanding of the organizational structure of SPCs, and how it helps the SPC to achieve its core objectives.

\subsection{The organizational structure ${ }^{1}$}

The organizational structure of SPC is an organizational framework through which the SPC defines and clarify roles and responsibilities within the SPC, delineates lines of authorities and communication and allocates rights and duties with regard to SPC members.

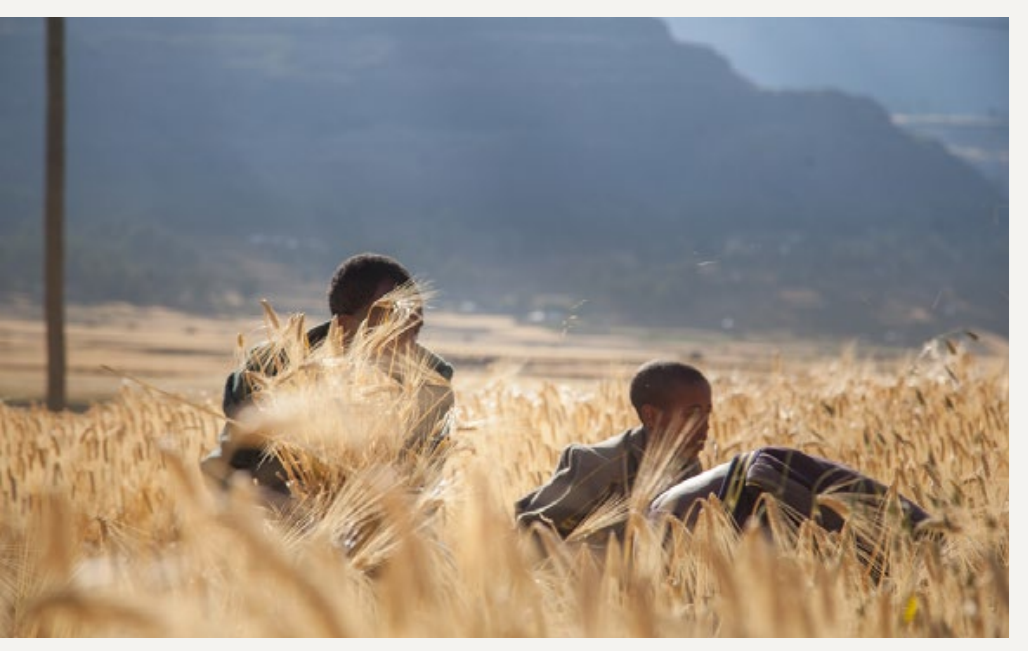

SPCs have an organizational structure that determines the relation between functions and positions and designates specific roles, responsibilities and authorities to carry out clearly defined seed business tasks. The organizational structure highlights how business tasks are planned, implemented, coordinated, monitored and evaluated, and how information and communication flows between the different levels of management. A typical SPC generally has four key levels in its organizational structure. It is fundamental that these four levels work together and actively engage with their designated responsibilities in relation to the strategic and operational management of the SPC. Ensuring that a SPC is adequately managed is a collaborative responsibility shared by SPC members and the different committees. 
Figure 2: Typical SPC organizational structure

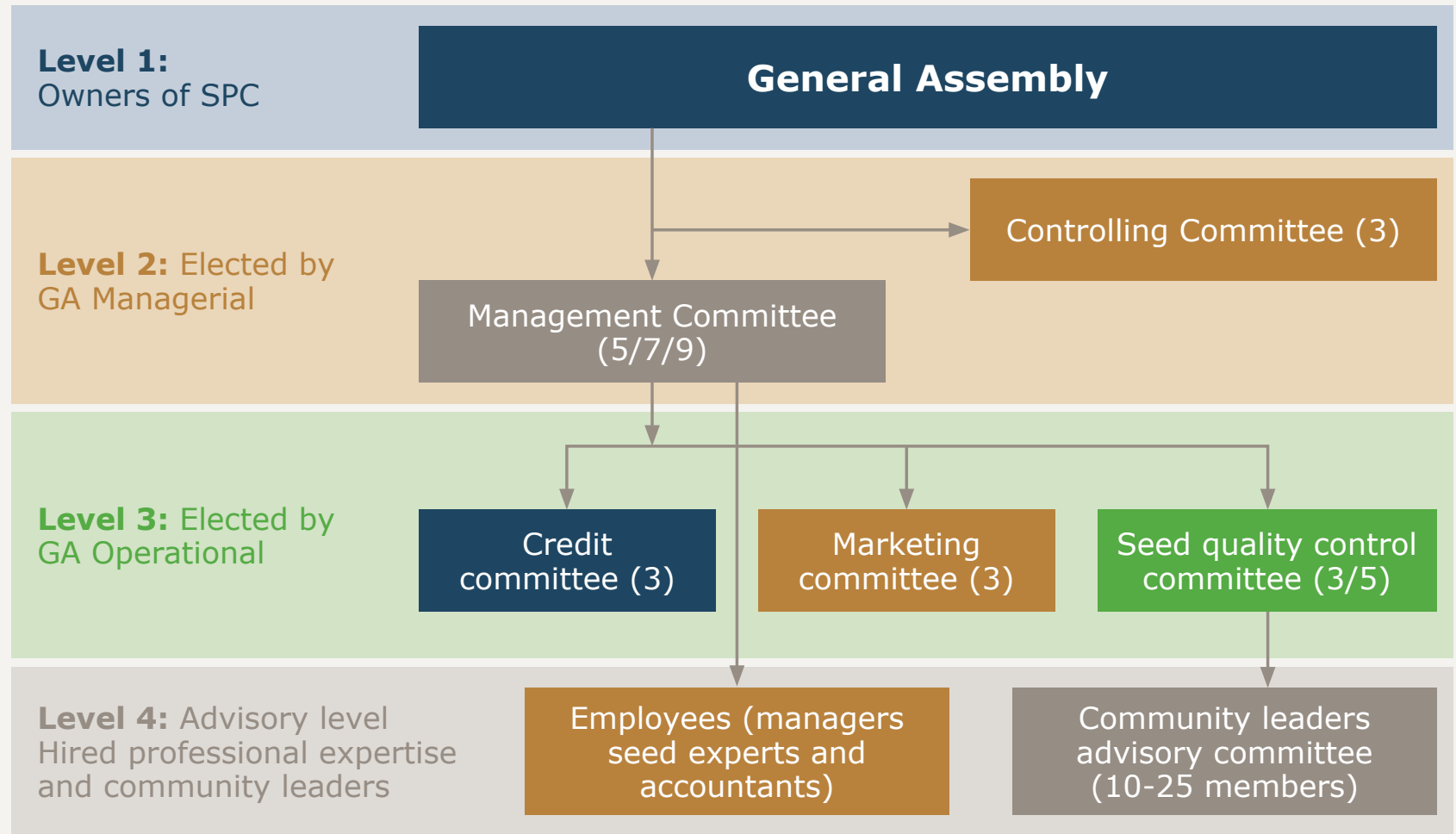

General assembly - SPC owners - level 1 Members of a particular SPC are the primary owners, users and controllers of the SPC. The members justify the continued existence of the SPC through their patronage, capital investment, and participation in decisionmaking. The members are represented in the organizational structure of the SPC by the general assembly. The general assembly has the mandate and responsibility to define the scope, ambitions, and activities of the SPC and to monitor and evaluate its overall performance.
The management committee -

SPC management - level 2

The management committee is a committee elected by the general assembly. It undertakes the duties and responsibilities assigned by the general assembly. Usually the management committee consists of five, seven or nine members (minimum five), based on total member size of the SPC and volume of seed business operation, who are elected to provide day to day leadership. The management committee is responsible for establishing policy, reporting to members and giving direction to the operation of the SPC. The tasks and responsibilities of the management committee are considered in detail in section 3 of this module. 


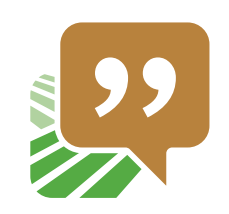

\section{SPCs experience from the field}

Case description: Before the beginning of ISSD support, most SPCs did not consider having a seed quality control committee in their organizational structure. But now many SPCs have formed and formally included internal seed quality control committees in their organizational structures. Nowadays it has become the norm that most SPCs elect three to five members at the general assembly to form a seed quality control committee.

Tailored capacity strengthening, in the form of tailored training, coaching and follow-up, has been provided to enhance the knowledge and skills of the members of the seed quality control committee. SPCs have recognized that the existence of an internal seed quality control committee has a positive impact and brings significant change, thus enabling the producing and selling of larger volumes of quality seed.

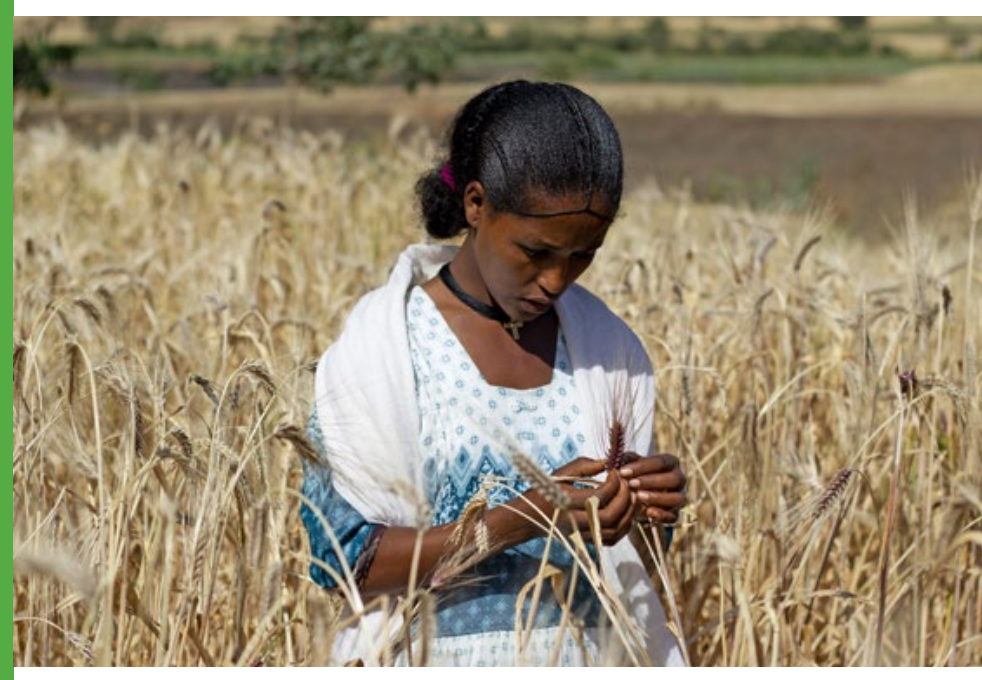

Field inspection of seed crop
The committee internally supervises and coaches member farmers in producing quality seed. This ensures the correct way of doing the following: site selection; land preparation; cluster formation; crop rotation practice; timely seed sowing; keeping and maintaining the right isolation distance between adjacent farms; freedom from weeds; harvesting with optimum seed moisture content; threshing on a clean threshing field; packing the product in clean seed bags/packs; and storing and preparing them to be sold and distributed to farmers.

Practical training provided to members, and continuous supervision and coaching received from the internal seed quality control committee, significantly improves members' awareness about how to produce quality seeds and increases the volume of quality seed produced each year. For a sample of 35 SPCs, the volume of quality seed increased by $22.8 \%$ from 2016 to 2018, which is largely attributed to improved internal quality control with the support of the seed quality control committee. 
The controlling committee -

\section{SPC management - level 2}

The general assembly elects three members to form the control committee. The control committee has the right and responsibility to oversee and monitor the adequate implementation of activities, the functioning of the SPC and the usage of SPC resources as agreed on by the general assembly and the management committee. The control committee can denounce and flag undesired behaviour if it has evidence to prove misdoings. The committee does not have decision-making powers or authority to implement any measures or resolutions.

\section{The seed quality control committee -} SPC operations - level 3

The internal seed quality control mechanism requires procedures that the SPC applies to control seed quality by itself, before the involvement of any external seed quality control authority. The SPC requires knowledge and skills to implement internal seed quality control mechanisms. Implementation of both internal seed quality control and external seed assurance ensures the supply of quality seed to famers, and protects genuine seed producers from unscrupulous producers.

\section{Seed marketing committee -}

\section{SPC operations - level 3}

The main responsibility of the seed marketing committee is to conduct periodic market studies and establish market linkages. By having a clear picture of the seeds that are in demand, what is needed, who needs it, and when it is needed, the SPC can be sure that there is demand for its products and that its supply meets the market demand. The committee participates in the forecast of seed demand. By analyzing the market demand, a forecast of the demand is made, which enables them to plan how much to produce and have an estimation of what would be sold.

The seed marketing committee is also required to be aware of and undertake seed promotion using various promotional channels. The committee creates awareness about the crop type and variety and adjust the volume and packaging of seeds according to market needs. In particular, for SPCs that engage in contract farming, the committee conducts market studies and price setting together with the SPC contractors and other partners.

Credit committee - SPC operations - level 3 Some SPCs establish a credit committee. This committee helps with internal loan and credit provision services to members by providing financial credit in cash or in kind (for instance, basic seed, fertilizer and other farm inputs). It is accountable to the general assembly, the management committee and the controlling committee.

Hired Employees (managers, seed experts, accountants, drivers) - SPC advisory level 4

Some SPCs hire employees. These are not members of the SPC. They have professional expertise, with experience and skills which make them suitable for employment for specific tasks and functions. Employees are accountable to the management committee. 
Community leaders' advisory committee - SPC advisory - level 4

On a voluntary basis, SPC members who are community leaders can form an advisory committee. The members of this committee have the right to participate in any SPC meetings and voice their opinion and views. It does not have a vote in decision making processes of the general assembly. This advisory body can be formed by highly trustable and respected leaders that have previously served an organizational function and whose opinion is valued and respected.

At level four any type of committee might be formed upon approval of the general assembly. Membership for a committee is based on members' voluntary support.

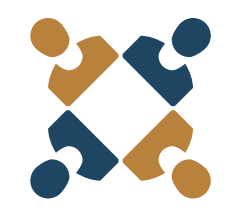

\section{Reflection questions}

In groups of three people, reflect on the following questions.

- What mechanisms can SPC members make use of to actively participate and engage with their organization?

- Why would a SPC consider hiring employees?

- What are the strengths and weaknesses of such an organizational structure?

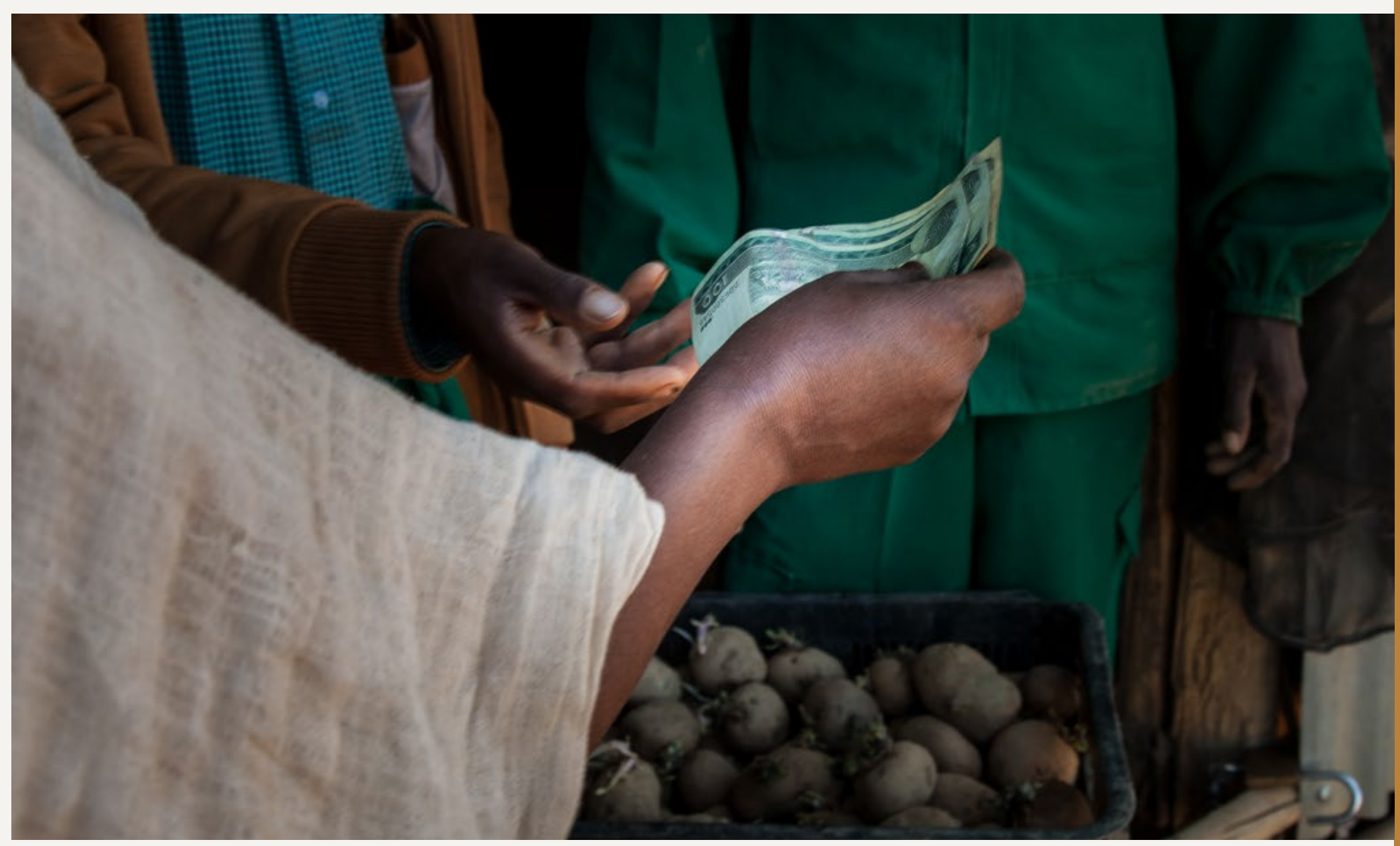




\section{SECTION 3 Management of SPCs}

The organizational structure of the SPC allows different committees to share roles and responsibilities with accountability. This cooperative management structure takes into consideration three levels of management: 1) strategic management, 2) operational management and 3 ) organizational management.

Strategic management and orientation is the responsibility of the general assembly which, through collective decision-making, traces strategic roadmaps and approves annual operational plans. The management committee is appointed by the general assembly to lead the organizational management of the SPC and oversee operational management, in coordination with its respective subcommittees.

\section{Specific learning objectives}

By the end of this session participants will be able to:

- summarize the key tasks and responsibilities of a SPC management committee

- differentiate between the tasks and responsibilities of the general assembly, the management committee, and internal sub-committees.

\subsection{Key characteristics of effective SPC organizational management}

The management committee is responsible for the organizational management of the SPC. Organizational management is the process of organizing, planning, leading and controlling resources, with the overall goal of achieving the SPC's defined objectives.

Effective organizational management calls for sound and timely decision making. It requires resolving emerging and unexpected issues in order for the SPC to be lucrative and effective in its provision of services and benefits to its members. Effective organizational management is a key factor for the success of any SPC.
Some of the issues to be considered by the management committee are: an effective and operational organizational structure; effective communication and collective decision making; and collectively agreed on strategic plans, operational plans, monitoring and evaluation. The management committee also determines optimum membership size; oversees the implementation of activities; ensures the division of tasks; and guarantees the day-to-day legal and autonomous operation of the SPC. The autonomy of the SPC is a particularly important issue that must be considered and actively pursued by the management committee. 


\subsection{Autonomy}

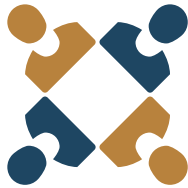

\section{Reflection questions}

In groups of three, reflect on the following question.

- What do you understand by the term 'autonomy' in the context of SPCs?

Autonomy is a principle that accentuates the independent and sovereign decision making authority of SPCs. The SPC, its leadership, and its management committee, must be autonomous. Autonomy is the degree to which the SPC makes significant and strategic decisions independently, regardless of the consent and opinion of others, be they the public, an NGO or a development partner. Autonomy, therefore, refers to the SPC's ability to run its business operations successfully, in the absence of the involvement or interference of external bodies or partners. Ideally, SPCs are fully autonomous in their capacity to decide on SPC issues, without interference from external parties.

\section{SPCs experience from the field}

\section{Organizational development as a driver for performance}

During the early years of ISSD operation, many SPCS had some level of dependence with regard to decisionmaking on their strategic issues and activities. As a result of their limited autonomy, many SPCS were unable to decide on what to produce, who to sell to, and for what price.

Through on-the-spot technical capacity building, the knowledge and skill of SPC management committees and other members of committees have improved considerably. This has included periodic visits to other SPCS to exchange experiences, and training on the rights and obligations of members, the cooperative proclamation, seed law, and SPC bylaws.

Consequently, the majority of the SPCs have become strong and autonomous local seed businesses. They have clearly structured organizations, in which the management committee oversees general operations and assigns tasks to relevant committee members and hired experts, basing investments and decisions on the tasks and responsibilities that each one is accountable for. Long-term success of a SPC can only be guaranteed when the SPC management committee stands by itself, is able to reach agreements with government and other stakeholders independently, and makes independent internal decisions based on its own internal strategic plans and the operations of its seed business. 


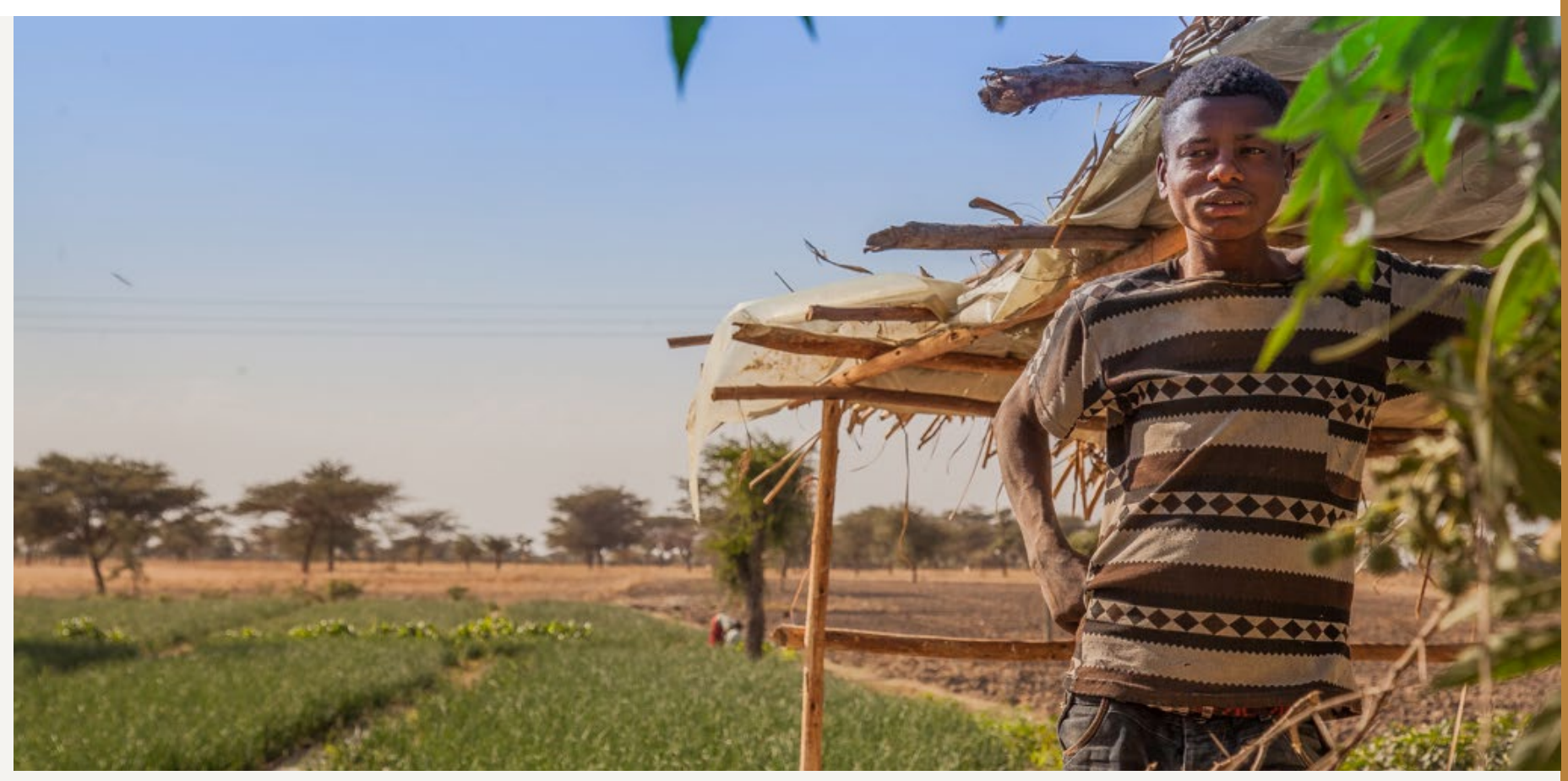

\subsection{Why division of tasks is important in the organizational structure of SPCS}

The organizational structure of the SPC allows different committees to share roles and responsibilities with accountability. However, absence and/or passiveness of structures may overburden a few members with a huge number of tasks to perform, resulting in inability to properly carry on activities, and hence reduced performance efficiency and effectiveness.

In some SPCs one can see the attempts of the management committee to centralize all responsibility and activities. The experience of ISSD is that this type of centrally administered and managed SPC often results in an inefficient SPC that does not promote democratic control and operational support from members of the SPC. In order to ensure adequate functioning of the different organizational structures of SPCs, and thereby ensure effectiveness and efficiency, the following actions are recommended.
- Organize periodic experience-sharing between SPCs that have similar performance, in order for them to learn from each other. Similarly, arrange benchmarking visits of less performing SPCs' committee members to observe and reflect on experiences and achievements of better performing SPCs which have attained autonomy in their seed business operations and decisionmaking.

- Discourage the existence of passive committees or members. Alternatively, raise their awareness of their responsibilities by facilitating independency, internal monitoring and evaluation mechanisms within the SPC.

- Facilitate the replacement of management committee members, that regardless of intervention have continued to be passive, when their terms of office end.

- Undertake coaching and monitoring to make sure that all the committees function according to their bylaws and the cooperative guidelines, and that they meet the demand of their business operations. 


\subsection{Key tasks of the SPC management committee}

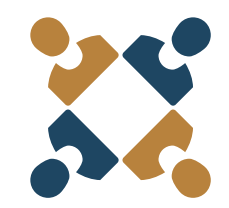

\section{Reflection questions}

In groups of three reflect on the following question.

- What are the main tasks of the management committee in your SPC?

A succinct, but by no means exhaustive, summary of the tasks of the management committee of the SPC is provided in the sections below.

\section{Planning}

The SPC management committee prepares an annual activity plan and budget and submits this to the annual general assembly for ratification and approval. The activity plan should incorporate all physical activities involved in the process of seed production and marketing.

\section{Organizing and coordinating resource investments}

The management committee is responsible for the efficient and effective investment of the SPCs available resources in accordance with a strategic plan and operational activity plan. The management committee organizes and coordinate all investments in a fully transparent manner.

\section{Monitoring and evaluation}

The management committee should make sure that all activities and investments are monitored and evaluated. The management committee can be supported in this task by the two controlling committees (the seed quality control committee and the supervisory committee). The main function of monitoring and evaluation is to oversee and monitor results; to evaluate performance and impact in relation to the targets set in the annual plan; and to build a learning agenda around the monitoring and evaluation. The two aforementioned controlling committees should organize and facilitate a meeting with the management and other subcommittees to perform an evaluation and observation of the seed farm and office management. The independent assessments identify and bring to light any gaps and deviations between actual performance and planned activities, and show the budget implications of these.

Transparency and accountability

SPCs are transparent and democratic organizations accountable to their members. Their management committees must therefore guarantee open communication, transparent processes (bookkeeping, decision making) and accountable documentation of all operations. The management committee must supply individual members and the general assembly with any type of requested information for internal control. The management committee has the responsibility to regularly call for general assembly meetings where they report on progress and results. Members have the obligation and right to participate in meetings and the right to report on meetings to others. 


\section{Decision-making}

Decision-making should be based on the principle of democratic member participation. Making sure that every voice is heard and accounted for is essential. Members should be allowed to set agenda points for the general assembly or management committee meeting. Minutes of meetings should be documented, encompassing all views reflected by members, so that active participation is reflected in the minutes. The SPC bylaws should contain a clear task division and description of the process of decision making. The management committee should always consult its members regarding strategic issues. They have to follow the bylaws, regulations and members' directions, rather than going by rule of thumb, which will create mistakes and go against rule of thumb. This practice gives room for the SPC to exercise its autonomy and become self-reliant in all areas of seed production and marketing.

\section{Members' active participation}

For SPCs, member participation in seed production and marketing is an important factor for success. Members are required to allocate their land for seed production, manage their seed field, and keep/maintain the quality of seed until it is stored in the seed store of the SPC. This entails effective, open and transparent communication, and needs the active engagement of the management committee and other committees.

It is important to consider that member participation should not be limited to seed production related activities. It is preferable for members' active participation to go beyond seed delivery and attract new members, investments and profit reinvestments, which will help the SPC to become financially autonomous and self-reliant.

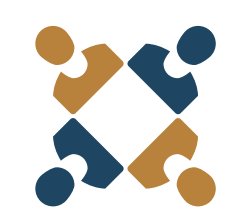

\section{Reflection questions}

In groups of three, reflect on the following questions.

- Describe six key responsibilities that SPC management committees must comply with?

- What relationship does the controlling committee have with the management committee?

- How can a management committee delegate operational responsibilities? 


\section{SECTION 4 Dos and don'ts}

\section{Learning objectives}

Based on the experiences of ISSD Ethiopia in supporting the organizational development of a SPC, there is much accumulated learning that needs to be shared with others. The following section summarizes some of this learning for participants, in order to:

- inform SPCs and their partners of real life experiences, highlighting what went well and what went wrong

- sharing experiences with those who are thinking of or in the process of setting up a SPC and want to learn from the experiences of others.

This bullet lists of dos and don'ts is just a starter, containing some elemental and basic issues about organizational management that need to be taken into consideration when establishing and supporting a viable and sustainable SPC.

\subsection{Dos}

- SPCs should be based on the land resources that are available, not just the number of farmers. A large area of land facilitates clustering of fields. The minimum land area should not be less than 5 hectare per cluster.

\section{- Engage and communicate with stake-} holders in the area you operate. Being aware of how your members and neighbours feel about the SPC can avoid unnecessary hiccups in your operations.

\section{- Ensure voluntary membership. There} should be no other means of bringing in members.

\section{- Make sure that SPC registration is according to the agreed-on registration standards. For instance, ensure that all members have committed enough shares; that the necessary financial paperwork has been done; that documents such as bank books are available, correct, and ready for inspection.}

\section{- Enforce bylaws actively to maintain} members' discipline as seed producers, committed to their duties and responsibilities. The SPC bylaws should always be updated to absorb new issues and organizational changes.

\section{- Clear and smart division of tasks in SPCs} should be in place; for instance, the key business interests of the SPC should be overseen by the quality control committee. In particular, the seed quality control committee should be central and very active in complying with its responsibilities, including inspecting, labeling, inviting the seed quality assurance authorities to visit for seed field inspections 
and seed sampling/testing, and other certification processes. All business aims should be for the highest quality of seed.

\section{- The SPC should provide basic member} services which require infrastructural investments, such as a cleaning machine, storage, threshing, and provision of inputs.

\section{- Encourage internal capitalization of}

SPCs to bolster autonomy and sustainability. SPCs should not be launched with huge investments from outside sources, especially when the member contributions (shares) are very small.

\section{Create adequate awareness within the} community for the establishment and organization of the SPC. Even if SPC registration is the sole mandate of the cooperative office, it is important to jointly engage farmers in the early stages of community mobilization. Awareness creation is key here; the supporting institution or expert should partner with the cooperative office to inject among the communities of interest the expectations from the supporting institution's point of view. This also helps the community of interest know with whom they are working and under which circumstances.

\section{- Follow up regularly and have a focal person at kebele level. Note that} organizing and registration of a SPC is just the start of a new challenge. Most of the failures in the management of the SPCS are when they start operating the actual seed business. Regardless of the bylaws and contractual obligations, members often start to act otherwise, for instance by side-selling their produce. It is, therefore, important to closely monitor and provide regular backstopping for newly established SPCs and for upgrading the performance of existing SPCs.

\section{- Encourage SPC leadership and} members to convene periodic regular meetings based on the bylaws. This can be on an annual or biannual basis.

\section{- Build capacity (technical, infrastructure} and logistics). Not all SPCs are equally effective in their management performance. Conducting experience-sharing, demanddriven training, providing working manuals, problem-solving coaching, backstopping, and investment in infrastructure development and logistics, are important in improving the management performance of SPCs.

\section{Provide regular consultation for SPCs on increasing the active participation} of members. Other than the personal presence of members in respective meetings, members should make practical contributions in many forms, including ideas, debate, additional investments, profit reinvestments, promoting the SPC and its benefits, building trust among members, and enabling peaceful conflict resolutions among members.

\section{Encourage SPCs to hire professionals} for the management of the business in general. But make sure that the strategical decision-making and 'member controlled' principle is safeguarded. 


\subsection{Don'ts}

- Do not align ownership of SPCs with any NGO or government office. The main duties of a cooperative office is to support the SPCs in their seed business. Ownership of SPCs goes to the members of the cooperative themselves, while external support to SPCs is open to any partner seeking to do so. Certain experiences show that ISSD supported SPCs are perceived by some individuals as if they were owned by the ISSD project. As a result, experts in the cooperative office sometimes are reluctant to support SPCs and discourage SPC members from actively participating. This has been one of the factors for the weakness of some SPCs.

\section{Do not give the impression in the} startup period of SPCs that external support will be poured in. Manage expectations (at the launching phase) while mobilizing farmers around a business proposition that guarantees income generation for those members who are actively committed in the seed business. One experience from ISSD is that cooperative offices often attempt to give indications to farmers that they will get many services and benefits from external sources, including NGOs, development projects and government organizations, when organized into SPCs; but this is incorrect; they will not. Nevertheless, farmers that are organized in cooperatives do have the possibility to work together with partners and stakeholders that they would not have access to as individual farmers

\section{- Do not interfere in the autonomy} (internal functioning and decision making) of SPCs. Neither supporting institutions nor cooperative offices should interfere in the internal affairs of the SPCs. Interference has been an impediment for the performance of SPCs. Interference ultimately cripples the empowerment potential and self-reliance of SPCs in key areas such as decision making, conflict management, and investment planning.

\section{- Avoid textbook training approaches,} especially when engaging farmer members of the SPC. All trainings should focus on how rather than what, so that farmers can easily apply what they have learned in dealing with challenges. Adult learning should be the approach, with both delivery and materials used.

\section{- Do not rely on a few SPC management} committees. This leads to establishment of corrupt networks and relationships. The whole membership should be empowered, not only individual members of the committees in the SPC. Experience shows that empowering every member of the SPC helps to build a sense of good SPC ownership, belongingness and trust. Office terms must be limited to three years in office, with the possibility of re-election only once, as cooperative law dictates. Sadly, there have some cases in which SPCs have found it difficult to replace their leaders because of interest seeking and unnecessary networks and relationships with external stakeholders and within the SPC. 


\section{- Do not limit capacity building training} to the leadership. Instead, all members should be allowed the same chances so that members can demonstrate strong commitment and be empowered to actively participate in the functions of the SPC. This could also avoid any exploitative behavior of a few leaders against their fellow member farmers. Moreover, the training model should be household-based, not household head-based, in order to empower women who are often not registered in the SPCs. Although land is jointly owned by husband and wife, often only the husband is registered as a member of the SPC and receives training. Involvement of women in training is of great significance because women do most of the pre- and post-harvest activities for quality seed production.

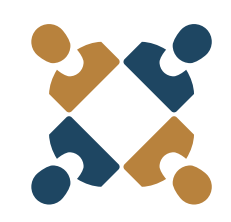

\section{Reflection questions}

In groups of three reflect on the following questions.

- What might cause SPCs to lose their autonomous decision-making capacity?

- How can SPCs benefit from capacity strengthening?

- Think of five issues that can make or break SPCs.

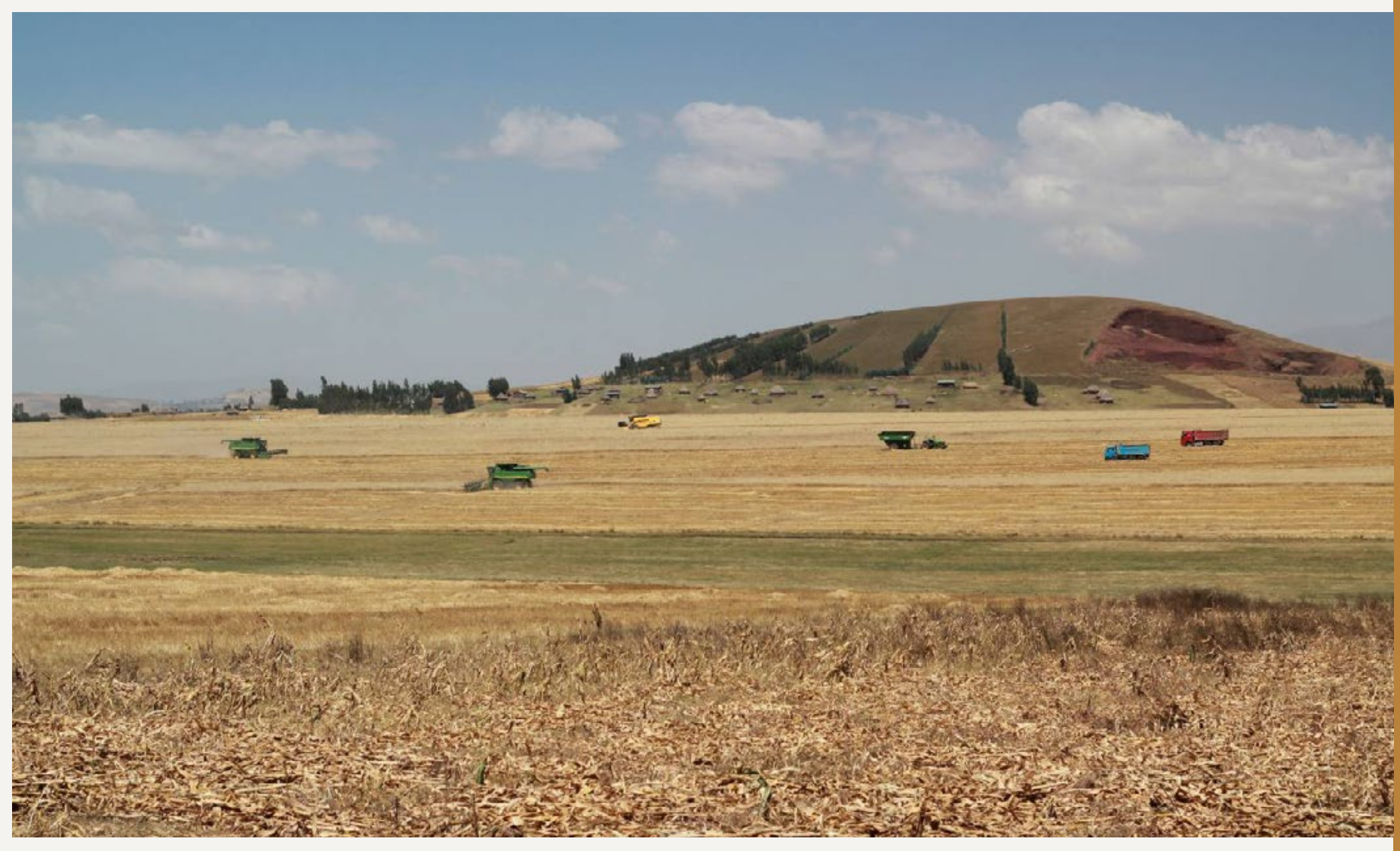




\title{
Bibliography
}

\begin{abstract}
URLs and links to internet sites contained in this module are provided for the convenience of the reader and are correct at the time of publication. ISSD Ethiopia takes no responsibility for the continued accuracy of that information or for the content of any external website.
\end{abstract}

Allen, L. Management and organization, McGraw-Hill, New York, 1958.

Banyo, S. The Concept of Organization (Formal and Informal) - A Review of Some Theories of Organizations and Human Behavior, 2014. https:// www.academia.edu/9264696/THE CONCEPT OF ORGANIZATION FORMAL_AND_INFORMAL_A_REVIEW_ OF_SOME_THEORIES_OF_ORGANIZATIONS_AND_HUMAN_BEHAVIOUR

Bauer, T., and others. Principles of Management, FlatWorld, Boston, MA, USA, 2016.

Boundless Management. Principles of Management, 2020.

https://courses. lumenlearning.com/ boundless-management/chapter/ principles-of-management/

Brock, D. Autonomy of Individuals and Organizations: Towards a Strategy Research Agenda. International Journal of Business and Economics, Vol. 2, No. 1, 57-73 (2003).

http://www.ijbe.org/table\%20of\%20 content/pdf/vol2-1/vol2-1-06.pdf
Federal Democratic Republic of Ethiopia. Seed Proclamation. Proclamation No. 782/2013, Addis Abeba, 2013.

https://chilot.files.wordpress. com/2014/09/proclamation-no782-2013-seed-proclamation.pdf

Federal Democratic Republic of Ethiopia. Cooperative Societies Proclamation. Proclamation No. 985/2016, Addis Abeba, 2016. https://www.ilo.org/dyn/natlex/ docs/ELECTRONIC/109318/135567/ F1774497447/ETH109318.pdf

International Labour Organisation (ILO). Resources for capacity building and training on cooperatives and other SSE enterprises, 2018. https://www.ilo.org/global/ topics/cooperatives/areas-of-work/ WCMS_628372/lang--en/index.htm

Management Study Guide. Organization Management; meaning, need and features. 2020. https://www. managementstudyguide.com/organizationmanagement.htm
Robbins, S. and others. Fundamentals of Management (10th Edition). Pearson, New York, 2016.

UK Department for International Development. Sustainable Livelihood Guidance Sheets, 1999. http://files.ennonline. net/attachments/871/dfid-sustainable-livelihoods-guidance-sheet-section 1.pdf

United Nations Development Programme Regional Centre for Latin America and the Caribbean. Guidance Note: Application of the Sustainable Livelihoods Framework in Development Projects. United Nations publication, 2017. https:// www. latinamerica.undp.org/content/rblac/en/home/library/poverty/ guidance-note--application-of-thesustainable-livelihoods-framew.html

Waldron, M. J., Vsanthakumar, J., and Arulraj, S. Improving the management of extension. In Improving management extension: a reference manual, Swanson, B. and others, eds. Rome, United Nations Food and Agriculture Organization, 1998. http://www.fao.org/3/w5830e0f.htm 